\title{
DIGITAL VERSUS MANUAL. TWO SIDES OF THE SAME COIN
}

\author{
Ingrid le Roux, University of Pretoria, South Africa
}

\section{Introduction}

In their preparation to educate future professionals, higher education institutions often employ innovating teaching methods, including games and simulations (Vlachopoulos \& Makri, 2017). Digital games and simulations have been used in entrepreneurship and business disciplines for many years and are designed to increase knowledge, improve skills and enable a positive learning environment in a realistic setting (Fox, Pittaway, \& Uzuegbunam, 2018). These simulations typically highlight the integration of business knowhow such as strategy, marketing, positioning and finance to help students understand how a business works (Caruso, 2018). Furthermore, the need for entrepreneurs to obtain and acquire certain skills for them to be successful cannot be over emphasised (Costin, O'Brain, \& Slattery, 2018). Digital game-based learning is recognised as creating effective learning environments, engaging learners cognitively, emotionally as well as socially (Huang, Johnson, \& Han, 2014).

It is important to acknowledge the rapid expansion in technology such as online learning but there is unfortunately also another reality. This other side of the coin often lies outside of higher education and normally in poor communities who are in dire need of attention. Disadvantaged learners in third world countries are in desperate need of acquiring business knowledge to enable them to better their situation and alleviate poverty. In many of these environments, the internet is not always available or, if available, data is too expensive for the ordinary citizen to afford and therefor digital game-based learning is not a reasonable option. The community of learners affected by the lack of resources are also in need of business knowledge and information to help them navigate the negative environment and equip them with hands-on learning by doing. In an attempt to address their specific needs, educators need to include such communities in their thinking, encourage innovation around business start-ups and provide a collaborative atmosphere for obtaining business know-how and develop human capital. A gap exists to develop new innovative and effective learning environment to create the same value for these learners. BDS, a board game simulation with a proven track record to transfer knowledge, involve learners and create an efficient learning environment (Le Roux, 2018) may be one solution to the existing gap.

The main aim of this study is to better understand, from a design perspective, how game features such as game structure, game involvement as well as game appeal are perceived and experienced when the simulation game is played manually. The three groups taking part in the study consist of post graduate (Honnours) students, full time third year entrepreneurship 
students as well as school exit level students. The study is based on Huang et al (2014) who used a digital game to determine the game features, motivational support and cognitive investment of learners. A board game simulation (BDS) was administered after which the participants reflected on their experience.

The contribution is to better understand if the BDS design caters for the different game features such as the game structure, game involvements as well as game appeal compared to that of a digital game-based simulation. Without the visual stimulation and features that characterise digital games, learners may lose interest in playing a manual game. BDS board game simulation can increase business and entrepreneurial know-how in an environment where youth unemployment is $47 \%$ through equipping youth and disadvantaged people in general with know-how to break out of the poverty cycle and create a business of their own.

\section{Literature Review}

\section{Simulations Games in Education and Training}

Simulations and educational games have a long history in management and other educational settings (Hodkiewicz, 2015). Business simulations as a pedagogy tool is an innovative and active learning experience with tremendous potential to enhance a student's comprehension of the fundamentals of business (Nugent, \& Brook, 2018). Simulation games are interactive experience-based learning environments as well as educational tools, valued because they combine input, application, reflection and feedback (Geithner \& Menzel, 2016). It creates a scenario-based environment, where participants interact to apply previous knowledge and practical skills to a real world problem (Vlachopoulus \& Makri, 2017). Simulations allow for a shift away from lecture-based education to an active learning method, theoretically grounded on Kolb's experiential learning theory (Kolb, 1984; Kolb \& Kolb, 2010). Simulations can be defined as a dynamic, simplified and accurate model of reality (Saive, Renaud, Kaufman, \& Marquis, 2007) where users learn about through interaction with the simulation (Alessi \& Trollip, 2001). Furthermore, simulations create a scenario-based environment where students interact as well as apply prior knowledge and practical skills to real-world problems. It allows participants to become active members and drivers of their own learning process. One of the differences between a manual and digital game is that the game is faster when played on a computer (Antonietti \& Mellone, 2003), but the players still acquire the same important skills such as teamwork, interpersonal communication, teamwork, leadership, decision-making, and stress management (Vlachopoulus \& Makri, 2017). However, the development of skills that enable students to face and meet the challenges of tomorrow is often undervalued (Geithner \& Menzel, 2016; p.229).

\section{The other side of the coin}

In South Africa, where the study was undertaken, unemployment is currently at its highest level since 1994 reported at $27 \%$ and increasing. Youth unemployment is at a staggering figure of more than $45 \%$ and in some areas is as high as $60 \%$. Companies are currently shedding jobs with the government sector as the only job creator. Creating a critical mass of 
entrepreneurs requires a long-term investment in human capital development, linking entrepreneurial training to enterprise development (Herrington, Kew, \& Mwanga, 2017). Introducing BDS, a start-up to growth board game simulation, could equip young people with the skills and experience to operate their own businesses successfully. This has potential positive effects in terms of profitability, survival of enterprises and long-term employment creation. Starting a new business is complex and requires a wide range of competencies and knowledge (Kriz \& Auchter, 2016). Board game simulations played around a table is of immense value where electricity, internet facilities and financial resources are limited. Using BDS, a start-up board game simulation to support the understanding of start-up activities through the venture life cycle business activities, this study aimed to better understand which game features were perceived by participants when playing the manual BDS game and if these features were perceived as positive or negative.

The main research question is: Can a non-digital board game simulation create the same perceived motivational impact/drive as a digital simulation? The sub questions are:

- How is the BDS game perceived in relation to digital game simulation features?

- How is the game structure perceived?

- How is the game involvement perceived?

- How is collaboration perceived?

- How is the feedback perceived?

- How is the experience of real business perceived?

Thus, the BDS used in this study is a simulation and not a game based on the following attributes: it is a simplified, dynamic and accurate model of a real start-up and growth experience and allows for decision-making in a secure, practical learning environment. Simulations have many benefits. Students are more involved, the simulation offers a space of freedom where mistakes can be made without negative consequences; it is a hands-on approach which allows for problem-solving, decision-making, critical thinking and taking personal responsibility for the outcome (Palmunen, Pelto, Paalumaki, \& Lainema, 2013; Geithner \& Menzel, 2016).

\section{Context and Data}

Over the past years' attempts were made to accredited the BDS board game as an educational tool for the transfer of business know-how in higher education to support learning and gaining practical business experience (Le Roux \& Steyn, 2007; Le Roux, 2017; 2018). With the rise in youth unemployment the game is now also used outside of formal educational settings and is perceived as a training tool for start-ups and small business owners. However, with the rapid development in digital games and simulations, the question arises if the board game without animation, soundtrack and other digital game features is still perceived as a valuable support tool in teaching and learning. The study was done with three different groups: two student groups and a group of school leavers. The student groups were from the University of Pretoria, South Africa. The first group consisted of Honours students who have done digital simulations as part of support learning in some of their courses. The second group was an 
undergraduate group specialising in entrepreneurship with an understanding of business but experience only of video games and gaming for fun. The final group consisted of a group of school leavers without the marks or means to enter a higher education institution potentially exposed only to video and gaming for fun experiences. The participants reflected on their experience after playing the BDS game using a questionnaire. The analysis comprised of depicting the data related to a Likert scale in pie charts as well as mean scores in Table 1. Each pie chart ( 1 being strongly disagree, 5 being agree strongly) represents the frequency to which each sample group scored questions on the Lickert scale (1 being strongly disagree, 5 being agree strongly).

\section{Findings}

The findings report on how participants perceived the game features of a manual board-game simulation. The design of an instructional game needs to enhance the learning process while the game features engage, motivate and allow for cognitive processing (Huang et al., 2012).

Table 1: $\quad$ Game Features and other variables

\begin{tabular}{lcccccc}
\hline \multicolumn{1}{c}{ Groups } & Structure & Involvement & Collaboration & $\begin{array}{c}\text { Knowledge } \\
\text { Information }\end{array}$ & Feedback & Reality \\
\hline Hons $\left(4^{\text {th }}\right)$ & $3.55^{*}$ & 3.97 & 4.43 & 3.82 & 3.80 & 3.64 \\
Undergrads & 3.8 & 4,32 & 4.58 & 3.81 & 3.87 & 3.84 \\
School leavers & 3.97 & 4.22 & 4.18 & 4.25 & 3.95 & 4.15 \\
\hline
\end{tabular}

* Scale of 1 to 5 where 1 - disagree strongly, 2 -disagree, 3 - unsure, 4 - agreed and 5 - agree strongly.

Table 1 shows a difference in perception on collaboration, knowledge information as well as reality. To give insight in Table 1, we use the following section shows pies charts for the following features namely structure, involvement, collaboration, knowledge Information, feedback and reality.

Figure 1 depicts the perceived level of structure experienced while playing the game. Game structure refers to several components such as rules, instructions, explanation and game tasks (Huang, Johnson, \& Han, 2012). 


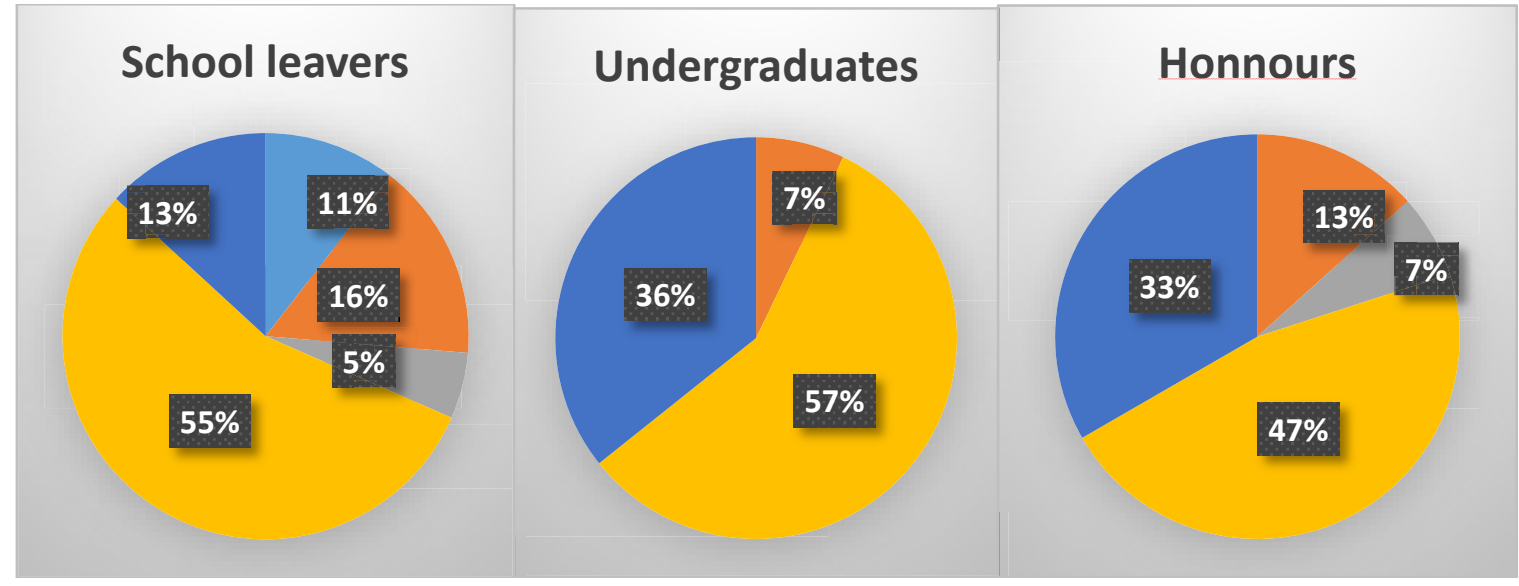

Figure 1. Perceived level of structure

(Dark blue - agree strongly; yellow - agree; grey - unsure; red - disagree; light blue - disagree strongly)

Eighty-two percent (82\%) of the school leavers perceived the tasks as clearly presented. The facilitators spent more time explaining the game to this group because they did not have the subject content and knowledge of the student groups. The undergraduate and post-graduate students received instruction sheets with the information, rules and guidelines to read with less time explaining the game at the beginning. However, that posed a problem because they did not want to spend time reading and just started to play. There appears support that the BDS as a manual game can provide the structure necessary for a motivated, conducive and effective learning environment.

Figure 2 depicts the level of involvement perceived by the different groups. Involvement refers to involvement features such as fun, fantasy and role-play (Huang, Johnson, \& Han, 2012) as well as motivation and engagement (Vlachopoulus \& Makri, 2017).

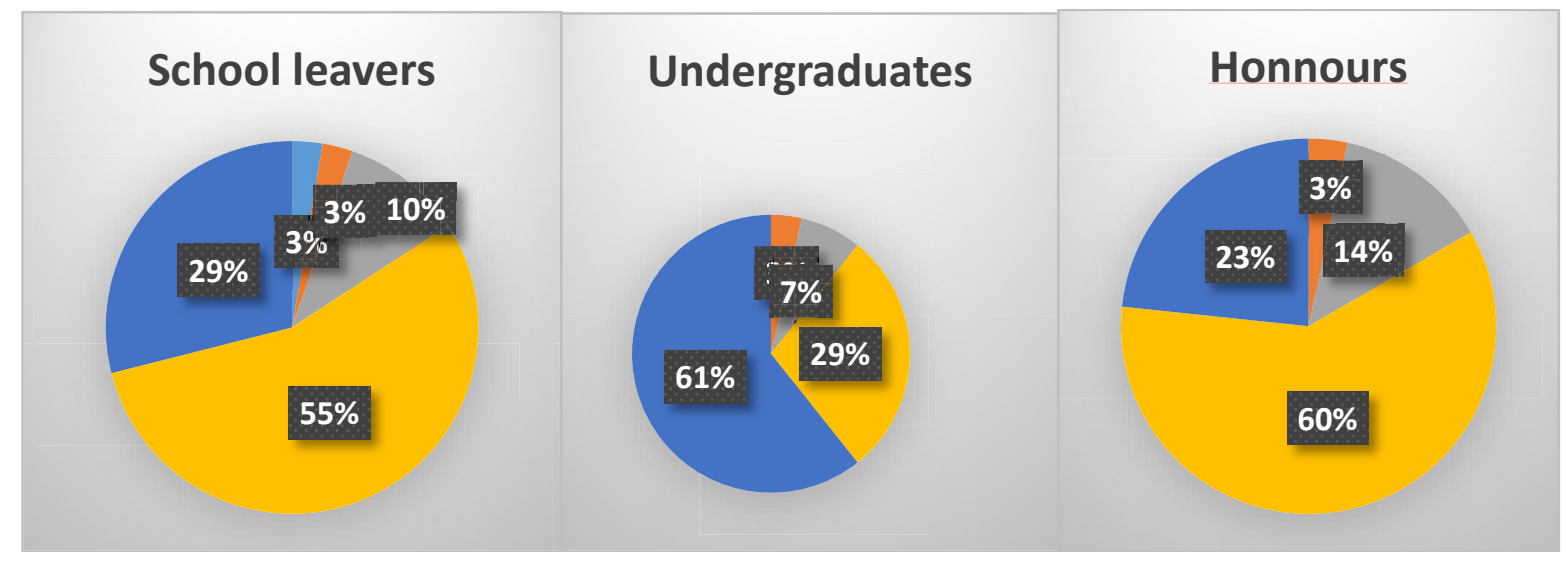

Figure 2. Perceived level of involvement

(Dark blue - agree strongly; yellow - agree; grey - unsure; red - disagree; light blue - disagree strongly)

Although there is no fantasy, animated features or audio graphics involved, merely replication of reality, the involvement level was still high. All three group scored their involvement as $80 \%$ and above. The participants appeared fully occupied by the learning tasks and engaged on a cognitive, emotional as well as social level (Huang, Johnson, \& Han, 2012). 
Figure 3 depicts the level of collaboration perceived by the different groups. Collaboration refers to interpersonal skills, communication, teamwork and leadership, decision making and stress management (Vlachopoulus \& Makri, 2017).

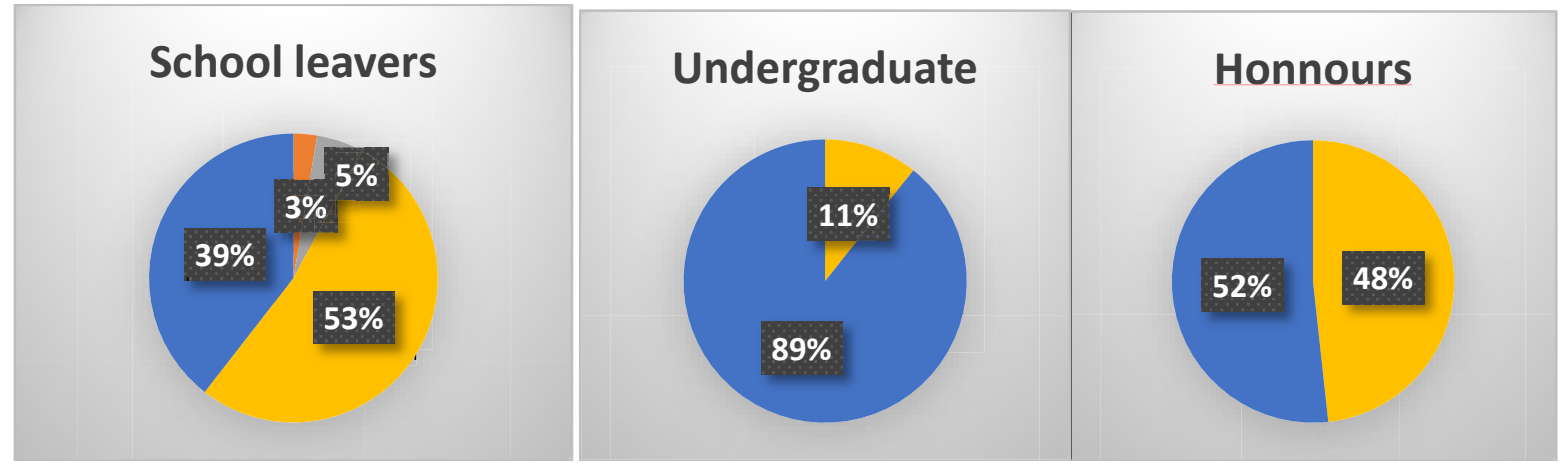

Figure 3. Perceived level of collaboration

(Dark blue - agree strongly; yellow - agree; grey - unsure; red - disagree; light blue - disagree strongly)

The participants were cognitively and emotionally involved, formed partnerships, but also tried to outsmart the other players. Although an element of competition was present (the person with the highest net asset value was the winner), participants understood the business principle of cooperation and participation to overcome working alone. The level of interaction and collaboration were high across all groups. However, the $89 \%$ of undergraduate students specialising in Entrepreneurship strongly agreed that collaboration was very high, $52 \%$ of post graduates and only 39\% of school leavers perceived the collaboration as high. This could be explained by the fact that the students studied at the same university for 3-4 years and knew each other, compared to the school leavers who came from different communities, schools and environments and did not know each other that well. It seems that that may be the reason for the lower level of perceived collaboration. This is an important finding and the facilitators should keep that in mind when starting a new training session. Facilitators and trainers of BDS need to allow adequate time for a get-to-know session before the actual training commences.

Figure 4 depicts the level of feedback received as perceived by the different groups. Meaningful feedback is seen as a key factor in participants achieving their objectives by reflecting on misunderstandings and mistakes to help them transfer learning to a new educational context (Vlachopolous \& Makri, 2017) 


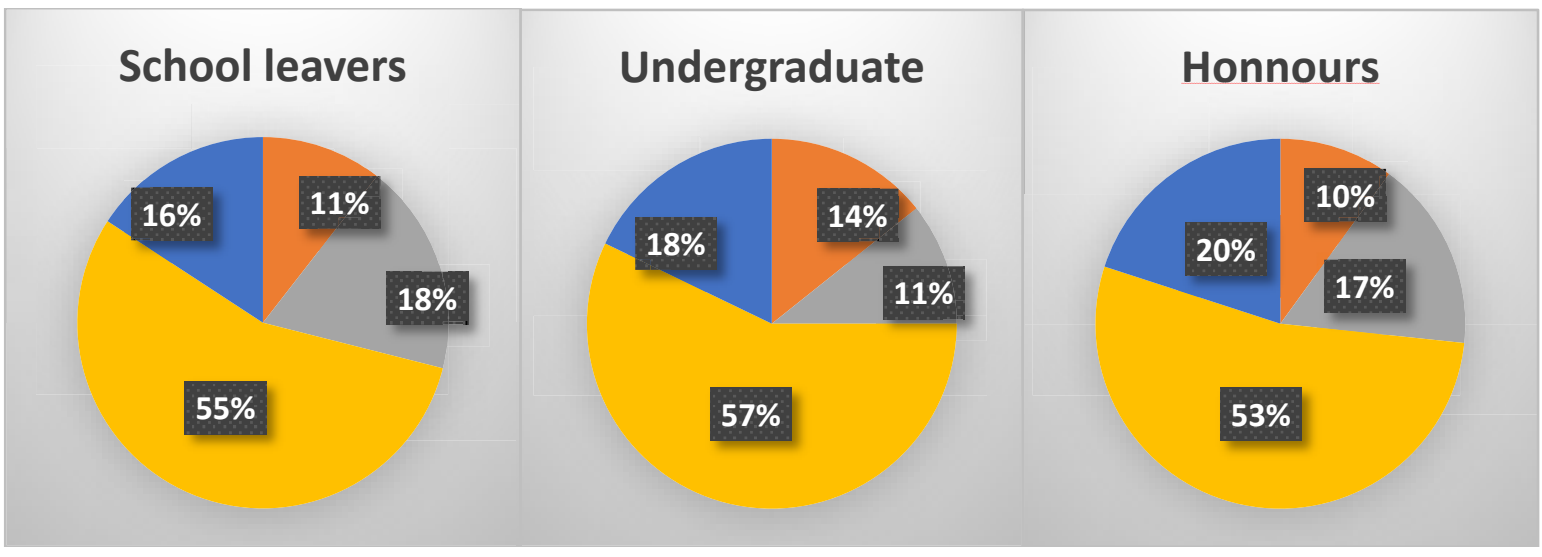

Figure 4. The perceived level of Feedback received

(Dark blue - agree strongly; yellow - agree; grey - unsure; red - disagree; light blue - disagree strongly)

The strongly agree and agree categories varied very little between the groups and consists of $70 \%$ and more. From the data it can be deducted that all three groups perceived the feedback as beneficial and necessary for their understanding and learning. Two facilitators administered the BDS game to make sure that participants received feedback on a continuous basis.

Figure 5 depicts the level of reality perceived by the different groups. Reality refers to the ability to represent real-world systems and enable participants to practice concepts relevant to the context. It represents a replica of reality, actual events, decisions making within a given context (Costin et al., 2018).

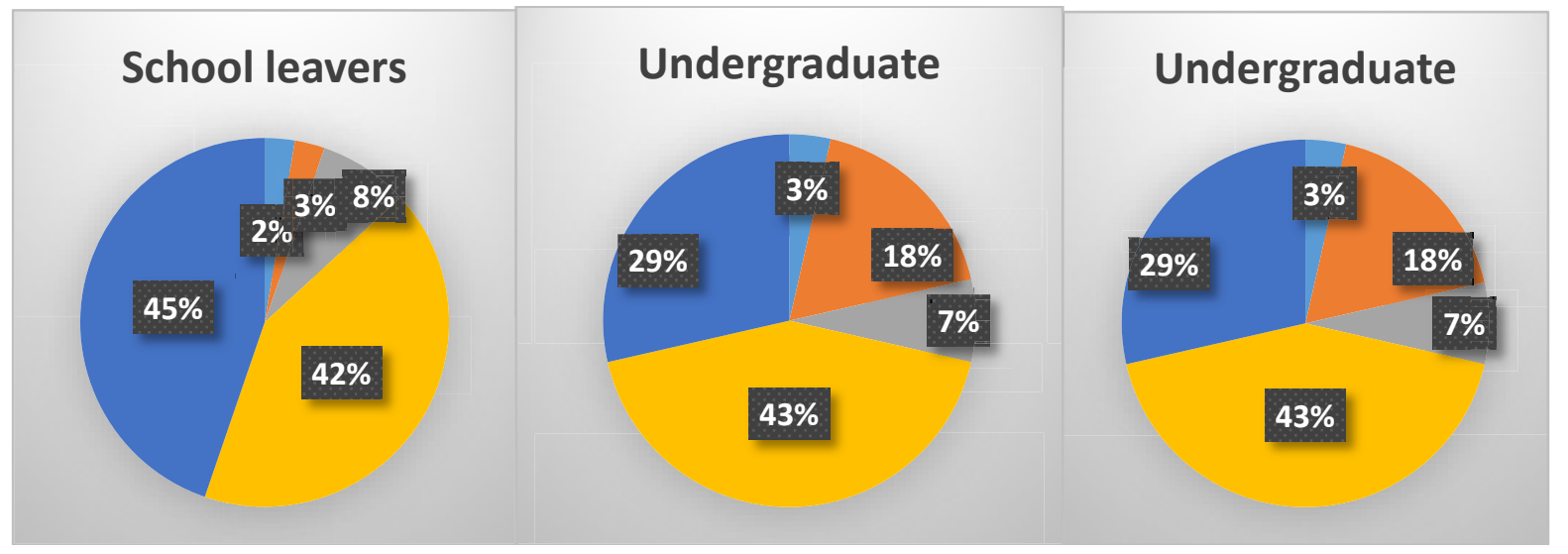

Figure 5: The perceived level of reality

(Dark blue - agree strongly; yellow - agree; grey - unsure; red - i; light blue - disagree strongly)

The school leaver group with no work experience and no additional business knowledge perceived the BDS games as high in representing a business start-up - much higher than the other two groups. As with the perceived levels of information and knowledge, this is possibly due to the fact that the two student groups, through their tertiary studies, have gained knowledge and experience through theory and case studies before participating in the BDS.

Figure 4 depicts the level of information and knowledge perceived by the different groups. 
Eighty-four percent (84\%) of school leavers perceived the information and knowledge gain as very high, $72 \%$ of undergraduates and $70 \%$ of the post-graduate students agreed. This could be explained by the fact that both student groups were students of entrepreneurship and thus had previous knowledge of the elements contained in the board game, whereas the school leavers had no previous knowledge of entrepreneurship and most of the information in the board game was brand new.

Although all the features as discussed in the above findings were present in the manual game, it is important to note that all three groups found the manual game challenging. Sixteen present of school leavers said that they did not find the game challenging which direct one to question their lack of business know-how and knowledge accumulated in their school years. In a written evaluation after the game one student reported: "I have learned more about doing business in this session than all my years at varsity (university)". Again a confirmation that learning by doing is perceived as more valuable than learning by listening.

\section{Conclusion}

The research question responds to the call for education to be effective, progressive but also serve the community. We implemented BDS, a non-digital board game simulation to determine if the participants perceived the same game features as favourably compared to a digital game-based simulation. It is of importance to determine if a manual game can create an effective learning environment, motivate participants and hold their attention.

From the data gathered, we made some tentative generalisations. It appeared evident that the board game simulation is valuable in creating a better understanding of how a start-up operates and grows. All three groups agreed that the game features presented were adequate and all felt that the game was challenging, the tasks were clearly defined, they received feedback on their performance, gained insight in a "real start-up" and it provided the opportunity to collaborate. It is interesting to see that the post-graduate group, with more experience than the other two groups, strongly agreed that the game provided them insight into a real start-up. Furthermore, the perceived opportunity for collaboration with others and the interaction around the table were high in all groups, but the highest in the third-year group.

The BDS manual game provides a solution in a setting where the environment is not conducive due to the lack of resources. It provides the same game features and may serve as a training solution for learners, small business as well as community members who are unemployed. BDS board game simulation provides the same game features as a digital game and therefore motivate and keep participants interested. It serves as a training tool to understand business start-up and growth which may serve as a solution to unemployment and poverty alleviation. Educators, trainers and other service providers need to relook the plight of people in a social setting that is not conducive for digital learning and allow manual games to fill the gap. 
Digital versus Manual. Two Sides of the Same Coin

Ingrid le Roux

\section{Limitations and recommendations}

All studies have limitations and the main limitation of this study is the small sample limited to South Africa.

A quantitative longitudinal study needs to be done to provide information if the game knowledge transferred relate to sustainable small businesses.

\section{References}

Alessi, S. M., \& Trollip, S. R. (2001). Multimedia for learning: methods and Development ( $3^{\text {rd }}$ ed.). Boston: Allyn and Bacon.

Antonietti, A., \& Mellone, R. (2003). The difference between playing games with and without the computer: A preliminary view. Journal of Psychology, 137, 133-144.

Caruso, J. V. (2018). Integrating Acumen and analytics: A simulation based approach. Development in Business Simulation and Experiential learning, 45, 231-233

Costin, Y., O’Brien, P., \& Slattery, D.M. (2018). Using simulation to develop entrepreneurial skills and mind-set: An exploratory case study. International Journal of teaching and learning in Higher Education, 30(1), 136-145.

Fox, J., Pittaway, L., \& Uzuegbunam, I. (2018). Simulations in Entrepreneurship Education: Serious Games and Learning Through Play. Entrepreneurship Education and Pedagogy, $1(1), 61-89$.

Geithner, S., \& Menzel, D. (2016). Effectiveness of learning through experience and reflection in a project management simulation. Simulation \& Gaming, 47(2), 228-256.

Herrington, M., Kew, P., \& Mwanga, A. (2017). South African Global Entrepreneurship report. Retrieved from https://www.gemconsortium.org/report/49833

Huang, W. D., Johnson, T. T., \& Han, S-H. C. (2012). Impact of online instructional game features on college students' perceived motivational support and cognitive investment: A structural equation modelling study. Internet and Higher Education, 17, 58-68.

Kolb, D. A. (1984). Experiential learning: experience as the source of learning and development. Englewood Cliffs, NJ: Prentice-Hall.

Kolb, Y. A., \& Kolb, D. A. (2010). Learning to play, playing to learn. A case study of a ludic learning space. Journal of Organisational Change Management, 23(1), 26-50.

Kriz, W. C., \& Auchter, E. (2016). 10 Years of Evaluation research into gaming simulation for German entrepreneurship and a new study on its long-term effect. Simulation \& Gaming, 47(2), 179-205.

Le Roux, I. (2018, June). Using a Blended Business Simulation (BDS) to gain practical business experience. Paper Presented at the Eden Annual Conference, 2018, Genoa.

Le Roux, I. \& Steyn, B. (2007). Experiential learning and critical reflection as a tool for transfer of business knowledge: An empirical case study of a start-up simulation 
intervention for nascent entrepreneurs. South African Journal of Economic and Management Science, 10(3), 330-347.

Nugent, M., \& Brook M. (2018). Business simulation performance after completing a reflective observation module. Development in Business Simulation and Experimental Learning, 45, 31-41.

Palmunen, L. M., Pelto, E., Paalumaki, A., \& Lainema, T. (2013). Formation of novice business students' mental models through simulation gaming. Simulation \& Gaming, 44(6), 846-868.

Saive, L., Renaud, L., Kaufman, D., \& Marquis, J-S. (2007). Distinguishing between games and simulations: A systemic review. Educational Technology \& Society, 10(3), 247-256.

Vlachopoulus, D., \& Makri, A. (2017). The effect of games and simulations on higher education: a systematic literature review. International journal of Educational Technology in Higher Education, 14, 22. 